\title{
ECG is an inefficient screening-tool for left ventricular hypertrophy in normotensive African children population
}

\author{
Giuseppe Di Gioia ${ }^{\text {Corresp., }}{ }^{1}$, Antonio Creta ${ }^{1}{ }^{\text {, }}$ Cosimo Marco Campanale ${ }^{1}$, Mario Fittipaldi ${ }^{2}$, Riccardo Giorgino ${ }^{1}$ \\ , Fabio Quintarelli ${ }^{3}$, Umberto Satriano ${ }^{1}$, Alessandro Cruciani ${ }^{1}$, Vincenzo Antinolfi ${ }^{4}$, Stefano Di Berardino ${ }^{5}$, \\ Davide Costanzo $^{1}$, Ranieri Bettini ${ }^{6}$, Giuseppe Mangiameli ${ }^{5}$, Marco Caricato ${ }^{5}$, Giovanni Mottini ${ }^{7}$ \\ 1 Department of Medicine and Surgery, Unit of Cardiology, Campus Bio-Medico University of Rome, Rome, Italy \\ 2 Paediatric Cardiothoracic Surgery, Starship Greenlane Paediatric and Congenital Heart Service, Auckland, New Zealand \\ 3 Department of Medicine and Surgery, Service of Pediatrics, Campus Bio-Medico University of Rome, Rome, Italy \\ 4 Heart and Great Vessels "Attilio Reale", University of Roma "La Sapienza", Rome, Italy \\ 5 Department of Medicine and Surgery, Geriatric Surgery Unit, Campus Bio-Medico University of Rome, Rome, Italy \\ 6 Cardiology Department, University of Pisa, Pisa, Italy \\ 7 Institute of Philosophy of Scientific and Technological Practise (FAST), Campus Bio-Medico University of Rome, Rome, Italy \\ Corresponding Author: Giuseppe Di Gioia \\ Email address: dottgiuseppedigioia@gmail.com
}

Background: Left ventricular hypertrophy (LVH) is a marker of pediatric hypertension and predicts development of cardiovascular events. Electrocardiography (ECG) screening is used in pediatrics to detect LVH thanks to major accessibility, reproducibility and easy to use compared to transthoracic echocardiography (TTE), that remains the standard technique. Several diseases were previously investigated, but no data exists regarding our study population. Aim of our study was to evaluate the relationship between electrocardiographic and echocardiographic criteria of LVH in normotensive African children. Methods: We studied 313 children (mean age 7,8 \pm 3 yo), in north-Madagascar. They underwent ECG and TTE. Sokolow-Lyon index was calculated to identify ECG-LVH (>35 mm). Left ventricle mass (LVM) with TTE was calculated and indexed by height ${ }^{2.7}$ $\left(\mathrm{LVMI}^{2.7}\right)$ and weight (LVMI $\left.{ }^{\mathrm{w}}\right)$. We report the prevalence of TTE-LVH using three methods: 1) calculating percentiles age- and sex- specific with values $>95^{\text {th }}$ percentile identifying $\mathrm{LVH}$; 2) LVMII $^{2.7}>51 \mathrm{~g} / \mathrm{m}^{2.7}$; 3) LVMI ${ }^{\mathrm{w}}>3.4 \mathrm{~g} /$ weight. Results: 40 (13\%) children showed LVMI values $>95^{\text {th }}$ percentile, 24 children $(8 \%)$ an $L V M l^{2.7}>51 \mathrm{~g} / \mathrm{m}^{2.7}$ while 19 children (6\%) an LVMI $^{w}>3.4 \mathrm{~g} / \mathrm{kg}$. LVH-ECG by Sokolow-Lyon index was present in 5, 3 and 3 children respectively, with poor values of sensitivity (ranging from 13 to 16\%), positive predictive value (from 11 to 18\%) and high values of specificity (up to $92 \%$ ). Effects of anthropometrics parameters on Sokolow-Lyon were analyzed and showed poor correlation. Conclusion: ECG is a poor screening test for detecting LVH in children. In clinical practice, TTE remains the only tool to be used to exclude LVH. 
$1 \quad$ ECG is an inefficient screening-tool for left ventricular hypertrophy in normotensive African children population

4 Giuseppe Di Gioia ${ }^{1}$, MD; Antonio Creta ${ }^{1}$, MD; Cosimo Marco Campanale ${ }^{1}$, MD; Mario 5 Fittipaldi², MD; Riccardo Giorgino ${ }^{1}$, MD student; Fabio Quintarelli ${ }^{3}$, MD student; Umberto 6 Satriano ${ }^{1}, \mathrm{MD}$ student; Alessandro Cruciani ${ }^{1}$, MD student; Vincenzo Antinolfi ${ }^{4}$, MD student; 7 Stefano Di Berardino ${ }^{6}$, MD student; Davide Costanzo ${ }^{1}$, MD student; Ranieri Bettini ${ }^{5}$, MD 8 student; Giuseppe Mangiameli ${ }^{6}$, MD; Marco Caricato $^{6}$, MD, FACS; Giovanni Mottini ${ }^{7}$, Prof.

${ }^{1}$ Department of Medicine and Surgery, Cardiology Unit, University Campus Bio-Medico, Rome, Italy

$11{ }^{2}$ Paediatric Cardiothoracic Surgery, Starship Greenlane Paediatric and Congenital Heart Service, 12 Auckland, New Zealand

${ }^{3}$ Department of Medicine and Surgery, Service of Pediatrics, University Campus Bio-Medico, Rome, Italy

${ }^{4}$ Department of Heart and Great Vessels “Attilio Reale”, La Sapienza University of Rome, Italy

${ }^{5}$ Cardiology Department, University of Pisa, Italy Italy 
22 Running Title: ECG screening for left ventricular hypertrophy.

23 Word count: 2538

24 Corresponding Author:

25 Giuseppe Di Gioia, MD; Department of Medicine and Surgery, Cardiology Unit, University Campus Bio-

26 Medico, Rome, Italy

27 Via Alvaro del Portillo, 200 - 00128 - Rome (Italy); Fax: 06/225411235 Tel: 06/225411133

28 Email: dottgiuseppedigioia@gmail.com

29 Conflict of interests: none.

30

31

32

33

34

35

36

37

38 


\section{Abstract}

42 Background: Left ventricular hypertrophy $(\mathrm{LVH})$ is a marker of pediatric hypertension and predicts development of cardiovascular events. Electrocardiography (ECG) screening is used in

44 pediatrics to detect LVH due to major accessibility, reproducibility and easier use compared to transthoracic echocardiography (TTE), which remains the standard technique. Several diseases were previously investigated, but no data exist regarding our study population. The aim of our study is to evaluate the relationship between electrocardiographic and echocardiographic criteria of LVH in normotensive African children.

Methods: We studied 313 children (mean age 7,8 \pm 3 y.o.), in north-Madagascar. They underwent ECG and TTE. Sokolow-Lyon index was calculated to identify ECG-LVH (>35 mm). Left ventricular mass (LVM) with TTE was calculated and indexed by height ${ }^{2.7}\left(\mathrm{LVMI}^{2.7}\right)$ and weight $\left(\mathrm{LVMI}^{\mathrm{w}}\right)$. We reported the prevalence of TTE-LVH using three methods: 1) calculating percentiles age- and sex-specific with values $>95^{\text {th }}$ percentile identifying LVH; 2) LVMI $^{2.7}>51$ $\left.\mathrm{g} / \mathrm{m}^{2.7} ; 3\right) \mathrm{LVMI}^{\mathrm{w}}>3.4 \mathrm{~g} /$ weight.

Results: $40(13 \%)$ children showed LVMI values $>95^{\text {th }}$ percentile, 24 children $(8 \%)$ an LVMI $^{2.7}$ $>51 \mathrm{~g} / \mathrm{m}^{2.7}$ while 19 children $(6 \%)$ an $\mathrm{LVMI}^{\mathrm{w}}>3.4 \mathrm{~g} / \mathrm{kg}$. LVH-ECG by Sokolow-Lyon index was present in 5, 3 and 3 children respectively, with poor values of sensitivity (ranging from 13 to $16 \%$ ), positive predictive value (from 11 to $18 \%$ ) and high values of specificity (up to $92 \%$ ). Effects of anthropometrics parameters on Sokolow-Lyon were analyzed and have shown poor correlation. 
61 Conclusion: ECG is a poor screening test for detecting LVH in children. In clinical practice,

62 TTE remains the only tool to be used to exclude LVH.

Introduction

Left ventricular hypertrophy $(\mathrm{LVH})$ in adults has received much attention since its detection is correlated to long-term clinical outcome, predicting cardiovascular events as

67 myocardial infarction, stroke and death [1-4]. LVH results from adaptation of the heart to increased hemodynamic burden, therefore early diagnosis is important, especially in children. In pediatric population LVH can be used as a marker to identify hypertensive children and predict development of future cardiovascular events [5]. Electrocardiographic (ECG) screening is widely used in pediatrics to detect and diagnose $\mathrm{LVH}$ and is considered a possible screening tool for hypertrophic cardiomyopathy [6], which is responsible for almost half of sudden cardiac death cases in developed countries [7]. Transthoracic echocardiography (TTE) is generally considered as the standard technique to diagnose $\mathrm{LVH}$, but ECG seems to be more attractive as a screening tool, especially in developing countries with less resources available, thanks to its lower costs, major accessibility and good reproducibility. ECG is also easily readable by non-specialist users compared to TTE. The validity of ECG criteria for diagnosing LVH has been previously studied in several diseases, such as pediatric hypertension [8], rheumatic heart disease [9], hypertrophic cardiomyopathy [10], HIV infection [11], aortic stenosis and ventricular septal defects [12]. This correlation remains to be determined in the population of this study, which is composed by

81 African normotensive children population. 

the relationship between electrocardiographic and echocardiographic criteria in a normotensive African children population.

\section{Material and Methods}

We performed a clinical, electrocardiographic and echocardiographic evaluation of 313 consecutive African children (ranging from 4 to 16 years old) describing the correlation between electrocardiographic and echocardiographic criteria for LVH. This study was conducted during a medical workcamp, coordinated by the Cardiovascular Department of Campus Bio-Medico of Rome, with the participation of cardiologists, pediatrics, pediatric cardiothoracic surgeons, surgeons and medical students. We had our main base at the "Clinique Médico-Surgicale St. Damien" of Ambanja, and we have investigated the region of Antsiranana, in the north of Madagascar, visiting the catholic schools of Sekoly Venance Manifatra "SE.VE.MA" and Foyer Mangafaly in Ambanja and the college Sainte Therese de l'Enfant Jesus in Maromandia, during the month of October 2015. In primary and high schools we randomly selected a class from each group of age to enroll individuals from 4 to 16 years. At the "Clinique St. Damien" we enrolled children who came for routine visits or screening, or in-patients. All individuals underwent 4 steps (see Figure 1). The first step consisted in registration into our database with name, surname (when available) and date-of-birth. Second step consisted in annotation of weight, height, body mass index (BMI) calculation, blood pressure, heart rate and cardiac auscultation. Auscultation was made by a pediatrician using a standard approach. The clinical questionnaire was perfomed 
104 by a visiting medical student aided and - when necessary - by a local interpreter who has been 105 educated in advance. Teachers or their coworkers helped the younger children understanding and

106

107

108

109

110

111

112

113

114

115

116

117

118

119

120

121

122

123

124

125

126

answering the questions. Third step consisted in a 12-leads ECG execution and a complete transthoracic echocardiogram for all the study-included subjects. Medical students - supervised by cardiologists - performed ECG according to international guidelines, by using a portable electro-cardiographer General Electric, Marquette MAC 5000 (GE, Milwaukee; USA) at a sampling rate of $150 \mathrm{~Hz}$, at standard paper speed $(25 \mathrm{~mm} / \mathrm{sec})$ and voltages $(10 \mathrm{~mm} / \mathrm{mV})$. ECG voltages, representing left ventricular forces, were calculated by hand for each ECG. Nonvoltage based anomalies, including $\mathrm{T}$ waves abnormalities were noted. Sokolow-Lyon index (SV1+RV5/RV6, mm) was calculated to identify children with electrocardiographic diagnosis of LVH (> $35 \mathrm{~mm})$. To calculate the left ventricular voltages, each patient's BMI was indexed to the age-based population-derived 50\% normative data for age, developing the formula: Indexed $\mathrm{ECG}$ voltage $=\left[\mathrm{ECG}\right.$ voltage $\left.\mathrm{x}\left(\mathrm{BMI}_{\mathrm{patient}} / \mathrm{BMI}_{50 \%}\right)\right][13]$. QTc interval was calculated with Bazett formula as follows: QT $/ \sqrt{ } \mathrm{RR}$. The upper normal limit was defined as $450 \mathrm{msec}$ for boys and $460 \mathrm{msec}$ for girls [14]. A team of cardiologists, with a portable echocardiograph (Esaote Mylab Five, Italy) equipped with a S5-1 transducer probe, performed TTE. All the exams were stored on appropriate supports. Subjects were studied in the left lateral recumbent position and all standard echocardiographic views were acquired. The LV inner dimensions were measured at end-diastole and end-systole using M-Mode echocardiography in the parasternal long axis view. End-diastole was defined as the frame following mitral valve closure; while end-systole as the frame following mitral valve opening. Left ventricular mass (LVM) was calculated based on Devereux's formula [15] and indexed [16] by height ${ }^{2,7}\left(\mathrm{LVMI}^{2.7}\right)$ or weight (LVMI'). In particular, LVM results from the formula: $\mathrm{LVM}=1 / 40.8 \times\left(1.04[\mathrm{LVIDd}+\mathrm{PWTd}+\mathrm{SWTd})^{3}-\right.$ 
$\left.\left.127(\mathrm{LVIDd})^{3}\right]\right)+0.6 \mathrm{~g}$, where LVIDd is the left ventricular internal dimension at the end diastole,

128 PWTd is the posterior wall thickness at the end diastole, and SWTd is the septal wall thickness at

129 the end diastole [17]. We report the prevalence of TTE-LVH by using three different methods

130 [18-22]: 1) calculating the population percentiles age- and sex-specific with values above the $95^{\text {th }}$

131 percentile identifying children with LVH; 2) LVMI value > 51 g/height ${ }^{2.7}$ [23]; 3) LVMI > 3.4

$132 \mathrm{~g} /$ weight. Because of widespread population illiteracy, written informed consent was difficult to 133 obtain. Indeed, a verbal informed consent - with teacher's help to translate the language - was

134 obtained from children's parents, who gave study approval to school's teachers and our research 135 group. The study was reviewed and approved before it began by ethics committees of University

136 Campus Bio-Medico of Rome (approval number $21.15 \mathrm{TS}$ ) and the project started in 137 collaboration with the doctors of hospital "Clinique Médico-Surgicale St. Damien" of Ambanja 138 that approved the study and approved the submission to the ethics committees of University 139 Campus Bio-Medico of Rome (since the lack of an Ethical committee in the local hospital 140 "Clinique Médico-Surgicale St. Damien” of Ambanja").

\section{Statistical analysis}

Categorical variables are expressed as frequencies and percentages in parentheses, and are compared by using Fisher's exact test or Chi-square test, as appropriate. Normality criteria were checked and met for any continuous variable, which is presented as mean and standard deviation and compared using Student t-test for independent data. Correlations between

147 continuous variables were calculated using Pearson's test. Considering the correlation between 148 Sokolow-Lyon Indexed and LVM as the primary end-point, we expected a correlation coefficient 
149 of 0.20 with an alpha error 0.05 and $90 \%$ power; this led us to calculate a sample size of 258

150 patients. The recruitment target was increased of $20 \%$ due to unexpected variability and final

151 sample size was of 313 children. The sensitivity, specificity, positive predictive value (PPV) and

152 negative predicting value (NPV) were calculated using $2 \times 2$ contingency tables. A P value less

153 than 0.05 was considered statistically significant. Statistical analysis was performed with

154 STATA Statistics for Windows (SE, version 13).

\section{Results}

313 children of African race were studied, with a slight prevalence of female sex (53\%).

Mean age was 7,8 \pm 3 years, ranging from 4 to 16 years. Clinical, electrocardiographic and echocardiographic features of population study are listed in Table 1. All children had normal arterial blood pressure. In 36 children (12\%) a cardiac murmur was detected at physical examination.

At ECG evaluation, in $19 \%$ of all children sinus rhythm was found with physiological sinus arrhythmia and sinus tachycardia (mean value $>100$ beats/minute) typical of the investigated range of age. Seven $(2 \%)$ children with short PR segment $(<120 \mathrm{msec})$ were identified. None of them had evident signs of pre-excitation or history of cardiac arrest. Abnormalities of $\mathrm{T}$ wave (prevalently flat $\mathrm{T}$ wave) were identified in 67 children $(21,4 \%)$. There was no correlation between clinical evaluation and evidence of ECG abnormalities: only 14 children had both a cardiac murmur and an ECG abnormality with a $21 \%$ sensitivity of clinical evaluation to predict ECG abnormalities, a 39\% PPV and a 91\% specificity. The QT interval was in the normal range 170 in all children under study. 28 children (9\%) presented a Sokolow-Lyon index $>35$ mm, having 
171 an ECG diagnosis of LVH. I degree AV block was present in only 2 children, so extra beats.

172 Positional Q waves were identified in 12 children while mild IV conduction delay (between 100

173 and 110 mesc) were present in 33 children. No bundle brunch blocks were identified.

174 At TTE evaluation, a mild mitral regurgitation (MR) was identified in 23 (7\%) children, while 3

175 children showed moderate MR. No severe MR were identified. Five cases of mild aortic

176 regurgitation (AR) were diagnosed with only one young boy having moderate AR. Only two

177 children showed mitral valve prolapse of anterior mitral leaflet with mild regurgitation. Five

178 congenital heart defects $(1,6 \%$ of children) were diagnosed: two inter-atrial defects, one child

179 with an inter-ventricular defect, one child with bicuspid aortic valve and one young girl with cor

180 triatriatum sinister. Only four children with cardiac murmur presented also an echocardiographic

181 evidence of valve regurgitation.

182 Following the work of Khoury et al. [24], which gave age-specific reference values for children's

183 LVMI, the 313 children in our study were divided according to age, sex and LVM as follows: 86

184 children $(27 \%)$ were in the $\leq 10^{\text {th }}$ percentile, $32(10 \%)$ were in the $25^{\text {th }}, 57(18 \%)$ in the $50^{\text {th }} ; 55$

$185(18 \%)$ in the $75^{\text {th }}, 30(10 \%)$ in the $90^{\text {th }}, 13$ children $(4 \%)$ in the $95^{\text {th }}$ and $40(13 \%)$ with values

186 above $95^{\text {th }}$ percentile.

187 The mean values of LVMI $\mathrm{g} / \mathrm{m}^{2.7}$ were $31,9 \pm 11,8 \mathrm{~g} / \mathrm{m}^{2.7}$ in the overall population, with only a 188 slight increase in children with an ECG-LVH diagnosis $\left(32,6 \pm 45,9 \mathrm{~g} / \mathrm{m}^{2.7}\right)$, while the mean 189 values for LVMI in $\mathrm{g} / \mathrm{kg}$ were $2,3 \pm 3 \mathrm{~g} / \mathrm{kg}$ for the overall population and 2,4 $\pm 3,4 \mathrm{~g} / \mathrm{kg}$ for the 190 children with an ECG-LVH diagnosis. 24 children (8\%) had an LVMI $2.7>51 \mathrm{~g} / \mathrm{m}^{2.7}$ while 19 191 children $(6 \%)$ showed an LVMI $^{\mathrm{w}}(>3.4 \mathrm{~g} / \mathrm{kg})$. Sensitivity, specificity, PPV and NPV of three 192 investigated methods to diagnose LVH are listed in Table 2. 
193 The capability of Sokolow-Lyon index to identify children with TTE-LVH appears to be very

194 poor. Only 5 children with ECG-LVH showed also an echocardiographic diagnosis of LVH (>

$19595^{\circ}$ percentile); only 3 children were identified with other two methods. The distribution of

196 children having an ECG-LVH according to LMVI percentiles is showed in Table 3. Values of

197 Sokolow-Lyon Index did not change according to LVMI percentiles (Figure 2).

198 Effects of anthropometrics parameters, including body surface area (BSA), BMI, height, weight,

199 and LVM (also indexed) on Sokolow-Lyon formula were analyzed (Figure 3) and showed poor

200 correlation. In the same way, when ECG voltages were indexed to patient's BMI (Sokolow-Lyon

201 Indexed), direct correlation with LVM and LVMI values (Figure 4) were not statistically

202 significant.

203 Physical parameters, such as weight, height, BMI and BSA had no independent effect in the

204 value of ECG parameters and the accuracy of the detection of LVH.

205 Authors acknowledge the fact that the reference value of Sokolow-Lyon $>35 \mathrm{~mm}$ to define LVH

206 is used in adults. We were not able to find a better cut-off in our young population. Considering

$207 \mathrm{LVMI}^{2.7}>51 \mathrm{~g} / \mathrm{m}^{2.7}$ to define echocardiographic LVH, the area under the ROC curve (Figure 5)

208 for the electrocardiographic Sokolow-Lyon Indexed was 0.496 (95\% CI 0.374-0.618, P value =

209 0.949). Therefore, a precise cutoff in our population could not be calculated accurately.

211 Discussion

212 This study has examined the correlation and the accuracy of ECG criteria to detect TTE-LVH in 213 a not hypertensive Malagasy children population. 
214 Cardiac magnetic resonance imaging and 3-dimensional echocardiography have proved to be

215 very accurate tools to diagnose and quantify LVH, but they are very expensive, they require 216 operator expertise and their use is unachievable in less developed countries where, most of the 217 time, it is difficult to submit population to an echocardiogram screening.

218 The ECG tool has been used since a long time to investigate heart anomalies. To date, there are 219 no clearly established benefits of a widespread, universal ECG screening in the young population $220[25,26]$. It is inexpensive compared to TTE or other imaging modalities, requires less specialist 221 skills and takes considerably less time.

222 In contrast, measuring LVH by TTE M-mode technique is relatively easy and quite available, 223 and actually the first method to be validated and currently the standard clinical diagnostic 224 method for detecting LVH [27].

225 Our study used different methods for the calculation of LVM.

226 In a population of not hypertensive children, ECG Sokolow-Lyon criteria analysis for the 227 detection of TTE-LVH suggests that ECG is a poor screening method for LVH.

228 More than 30 different ECG criteria exists for the detection of LVH on standard 12 leads ECG.

229 In a review [28] of 21 studies including more than 5000 hypertensive patients, using six different

230 ECG criteria, the authors concluded that ECG criteria cannot be used to exclude LVH in adult

231 hypertensive patients. However, many of the criteria used in adult subjects cannot be applied to a 232 children population of different age, gender and body surface area.

233 Previously several studies have examined a variety of ECG parameters in children, but our type 234 of population was not investigated before. 
235 The discordance between ECG criteria and TTE-LVH has been described in several pediatric

236 disease states, such as rheumatic heart disease [9], myocarditis [29] and hypertrophic

237 cardiomyopathy [10,30,31].

238 In children with rheumatic heart disease [9], sensitivity and specificity of ECG were $68 \%$ and

$23976 \%$ respectively. Sensitivity in hypertrophic cardiomyopathy reached $76 \%$ [30].

240 Rivenes et al. [11] investigated children with human immunodeficiency virus (HIV) infection;

241 prevalence of ECG-LVH was 7.4\% with sensitivity less than $20 \%$ and $90 \%$ specificity but used

242 ECG-LVH criteria by Davignon [32], which are not gender specific.

243 Rijnbeek et al. [21] reported a study of 832 unselected pediatric hospital population using wide 244 types of parameters for ECG-LVH detection, reporting a less than $25 \%$ sensitivity.

245 In diseases with pressure or volume ventricular overload as aortic valve stenosis or ventricular 246 septal defect, Fogel [12] et al. found that, regardless of age, Sokolow-Lyon criteria were 247 statistically higher compared to normal children, with the highest sensitivity in aortic stenosis 248 patients $(67 \%)$.

249 The study by Monganroth et al. [33] found excessive values of sensitivity of ECG criteria with 250 false-positive diagnosis in an adolescent cohort with no TTE-LVH, but LVM was not indexed to 251 BSA.

252 An interesting data that emerged from our study was the high prevalence of children showing $253 \mathrm{LVH}$, revealed both from the value of $\mathrm{LVMI}^{2.7}$, adjusted by age and sex ( 24 children, $8 \%$ ), from $254 \mathrm{LVMI}>95^{\text {th }}$ percentile $(40$ children, $13 \%)$ and $\mathrm{LVMI}^{\mathrm{w}}(19$ children, $6 \%)$. In fact, the prevalence 
255 of LVH in pediatric hypertensive population has been reported to vary from $8 \%-41 \%$ depending

256 on the criteria used for determining hypertension and LVMI [34-39].

257 ECG is an easily obtainable, low cost, rapid test but with several limitations that do not allow to 258 substitute a TTE evaluation, even in developing countries, where less resources are available.

259 Nowadays, ECG screening is used in many preparticipation sports screening programs to detect 260 cardiac abnormalities. ECG is a poor screening method for LVH, with very low values of 261 sensitivity in general population, as demonstrated by our study in normotensive children. Other 262 studied showed similar values for hypertensive children and, at best, modest values of specificity 263 and sensitivity where reached, in diseases affecting directly left ventricular mass or pressure264 loading conditions like aortic stenosis or hypertrophic cardiomyopathy, but non obtaining 265 optimal value to consider ECG as a valid screening method. Echocardiography remains the best 266 clinical tool for LVH screening in pediatric population.

\section{Conclusion}

269 In a normotensive African population, ECG is a poor screening test for the detection of LVH in 270 children. In clinical practice, TTE remains the only tool to be used to exclude LVH.

272 Acknowledges: none.

273 References 
274

275

276

277

278

279

280

281

282

283

284

285

286

287

288

289

290

291

292

293

294

295

296

1. Devereux RB, Bella J, Boman K, Gerdts E, Nieminen MS, Rokkedal J, Papademetriou V, Wachtell K, Wright J, Paranicas M, Okin PM, Roman MJ, Smith G, Dahlöf B. Echocardiographic left ventricular geometry in hypertensive patients with electrocardiographic left ventricular hypertrophy: the LIFE Study. Blood Press 2001;10:74-82.

2. Koren MJ, Devereux RB, Casale PN, Savage DD, Laragh JH. Relation of left ventricular mass and geometry to morbidity and mortality in uncomplicated essential hypertension. Ann Intern Med 1991;114:345-52.

3. Brown DW, Giles WH, Croft JB. Left ventricular hypertrophy as a predictor of coronary heart disease mortality and the effect of hypertension. Am Heart J 2000;140: 848-56.

4. Levy D, Garrison RJ, Savage DD, Kannel WB, Castelli WP. Prognostic implications of echocardiographically determined left ventricular mass in the Framingham Heart Study. N Engl J Med 1990;322:1561-6.

5. Hanevold C, Waller J, Daniels S, Portman R, Sorof J. The effects of obesity, gender and ethnic group on left ventricular hypertrophy and geometry in hypertensive children: a collaborative study of the International Pediatric Hypertension Association. Pediatrics 2004;113:328-33.

6. Gersh BJ, Maron BJ, Bonow RO, Dearani JA, Fifer MA, Link MS, Naidu SS, Nishimura RA, Ommen SR, Rakowski H, Seidman CE, Towbin JA, Udelson JE, Yancy CW; American College of Cardiology Foundation/American Heart Association Task Force on Practice Guidelines; American Association for Thoracic Surgery; American Society of Echocardiography; American Society of Nuclear Cardiology; Heart Failure Society of America; Heart Rhythm Society; Society for Cardiovascular Angiography and 
Interventions; Society of Thoracic Surgeons. 2011 ACCF/ AHA guidelines for the diagnosis and treatment of hypertrophic cardiomyopathy: a report of the American College of Cardiology Foundation/ American Heart Association Task Force on Practice Guidelines. Circulation. 2011;124:e783-e831.

7. Maron BJ, Gardin JM, Flack JM, Gidding SS, Kurosaki TT, Bild DE. Assessment of the

B, Oesman I. Sensitivity and specificity of electrocardiographic criteria for left ventricular hypertrophy in children with rheumatic heart disease. Pediatr Indones 1991;31:233-44.

10. Panza JA, Maron BJ. Relation of electrocardiographic abnormalities to evolving left ventricular hypertrophy in hypertrophic cardiomyopathy during childhood. Am J Cardiol 1989;63:1258-65.

11. Rivenes SM, Colan SD, Easley KA, Kaplan S, Jenkins KJ, Khan MN, Lai WW, Lipshultz SE, Moodie DS, Starc TJ, Sopko G, Zhang W, Bricker JT. Usefulness of the pediatric electrocardiogram in detecting left ventricular hypertrophy: results from the prospective Pediatric Pulmonary and Cardiovascular Complications of Vertically Transmitted HIV Infection Multicenter Study. Am Heart J 2003;145:716-23. 
319

320

321

322

323

324

325

326

327

328

329

330

331

332

333

334

335

336

337

338

339

340

12. Fogel MA, Lieb DR, Seliem MA. Validity of electrocardiographic criteria for left ventricular hypertrophy in children with pressure- or volume-loaded ventricles: comparison with echocardiographic left ventricular muscle mass. Pediatr Cardiol 1995; $16: 261-9$.

13. Czosek RJ, Cnota JF, Knilans TK, Pratt J, Guerrier K, Anderson JB. Relationship between echocardiographic LV mass and ECG based left ventricular voltages in an adolescent population: related or random? Pacing Clin Electrophysiol. 2014 Sep;37(9):1133-40.

14. Pearl W. Effects of gender, age, and heart rate on QT intervals in children. Pediatr Cardiol. 1996 May-Jun;17(3):135-6.

15. Devereux RB, Alonso DR, Lutas EM, Gottlieb GJ, Campo E, Sachs I, Reichek N. Echocardiographic assessment of left ventricular hypertrophy: comparison to necropsy findings. Am J Cardiol 1986;57:450-8.

16. National High Blood Pressure Education ProgramWorking Group on High Blood Pressure in Children and Adolescents. The fourth report on the diagnosis, evaluation, and treatment of high blood pressure in children and adolescents. Pediatrics 2004;114:555-76.

17. Lang RM, Badano LP, Mor-Avi V, Afilalo J, Armstrong A, Ernande L, Flachskampf FA, Foster E, Goldstein SA, Kuznetsova T, Lancellotti P, Muraru D, Picard MH, Rietzschel ER, Rudski L, Spencer KT, Tsang W, Voigt J. Recommendations for cardiac chamber quantification by echocardiography in adults: an update from the American Society of Echocardiography and the European Association of Cardiovascular Imaging. J Am Soc Echocardiogr. 2015 Jan;28(1):1-39.e14. 
341 18. de Simone G, Daniels SR, Devereux RB, Meyer RA, Roman MJ, de Divitiis O,

20. de Simone G, Devereux RB, Daniels SR, Koren MJ, Meyer RA, Laragh JH. Effect of growth on variability of left ventricular mass: assessment of allometric signals in adults and children and their capacity to predict cardiovascular risk. J Am Coll Cardiol $1995 ; 25: 1056-62$.

21. Rijnbeek PR, van Herpen G, Kapusta L, Ten Harkel AD, Witsenburg M, Kors JA. Electrocardiographic criteria for left ventricular hypertrophy in children. Pediatr Cardiol 2008;29:923-8.

22. Overbeek LI, Kapusta L, Peer PG, de Korte CL, Thijssen JM, Daniels O. New reference values for echocardiographic dimensions of healthy Dutch children. Eur J Echocardiogr 2006;7:113-21.

23. Hanevold C, Waller J, Daniels S, Portman R, Sorof J. International Pediatric Hypertension Association. The effects of obesity, gender, and ethnic group on left ventricular hypertrophy and geometry in hypertensive children: a collaborative study of the International Pediatric Hypertension Association. Pediatrics. 2004 Feb;113(2):328-33. 
362

363

364

365

366

367

368

369

370

371

372

373

374

375

376

377

378

379

380

381

382

383
24. Khoury PR, Mitsnefes M, Daniels SR, Kimball TR. Age-specific reference intervals for indexed left ventricular mass in children. J Am Soc Echocardiogr. 2009 Jun;22(6):70914.

25. Sharma S, Estes NA 3rd, Vetter VL, Corrado D. Clinical decisions: cardiac screening before participation in sports. N Engl J Med. 2013;369:2049- 2053.

26. Fuller CM. Cost effectiveness for screening high school athletes for risk of sudden cardiac death. Med Sci Sports Exerc. 2000;32:887-890.

27. Alfakih K, Reid S, Hall A, Sivananthan MU. The assessment of left ventricular hypertrophy in hypertension. J Hypertens 2006;24:1223-30.

28. Pewsner D, Jüni P, Egger M, Battaglia M, Sundström J, Bachmann LM. Accuracy of electrocardiography in diagnosis of left ventricular hypertrophy in arterial hypertension: systematic review. BMJ 2007;335:711.

29. Oda T, Hamamoto K, Morinaga H. Left ventricular hypertrophy in non-rheumatic myocarditis in children. Jpn Circ J 1982;46:1235-1238.

30. Louie EK, Maron BJ. Hypertrophic cardiomyopathy with extreme increase in left ventricular wall thickness: functional and morphologic features and clinical significance. J Am Coll Cardiol 1986;8:57-65

31. Maron BJ, Wolfson JK, Ciro E, Spirito P. Relation of electrocardiographic abnormalities and patterns of left ventricular hypertrophy identified by 2-dimensional echocardiography in patients with hypertrophic cardiomyopathy. Am J Cardiol 1983;51:189-194.

32. Davignon A, Rautaharju P, Boisselle E. Normal ECG standards for infants and children. Pediatr Cardiol 1979;1:123-31. 
384

385

386

387

388

389

390

391

392

393

394

395

396

397

398

399

400

401

402

403

404

405
33. Morganroth J, Maron BJ, Krovetz LJ, Henry WL, Epstein SE. Electrocardiographic evidence of left ventricular hypertrophy in otherwise normal children: clarification by echocardiography. Am J Cardio 1975;135:278-281.

34. Brady TM, Fivush B, Flynn JT, Parekh R. Ability of blood pressure to predict left ventricular hypertrophy in children with primary hypertension. J Pediatr 2008; 152:73-8. 78.e1.

35. Daniels SR, Loggie JMH, Khourt P, Kimball TR. Left ventricular geometry and severe left ventricular hypertrophy in children and adolescents with essential hypertension. Circulation 1998;97:1907-11.

36. Daniels SD, Meyer RA, Loggie JMH. Determinants of cardiac involvement in children and adolescents with essential hypertension. Circulation 1990;82:1243-8.

37. Sorof J, Cardwell G, Franco K, Portman RJ. Ambulatory blood pressure and left ventricular mass index in hypertensive children. Hypertension 2002;39:903-8.

38. Laird WP, Fixler DE. Left ventricular hypertrophy in adolescents with elevated blood pressure: assessment by chest roentgenography, electrocardiography and echocardiography. Pediatrics 1981;67:255-9.

39. Niederle P, Widimsky J, Jandova R, Ressl J, Grospic A. Echocardiographic assessment of the left ventricle in juvenile hypertension. Int J Cardiol 1982;2:91-101. 
406

407

408

409

410

411

412

413

$414 \quad$ Figures

415 Figure 1 


\section{STEP: CHILDREN EVALUATION}

- Demographic data

\section{STEP: PHYSICAL EXAMINATION}

- Height, weight, BMI

\section{STEP: ECG}

- Sokolow-Lyon formula for ECG-LVH diagnosis

\section{STEP: ECHOCARDIOGRAM}

LVH diagnosis using three formulas:

- Percentiles age- and sex- specific; g/height ${ }^{2.7} ; \mathrm{g} /$ weight

416

417 Figure 1. Flow-chart of children's evaluation. 


\section{$423 \quad$ Figure 2}

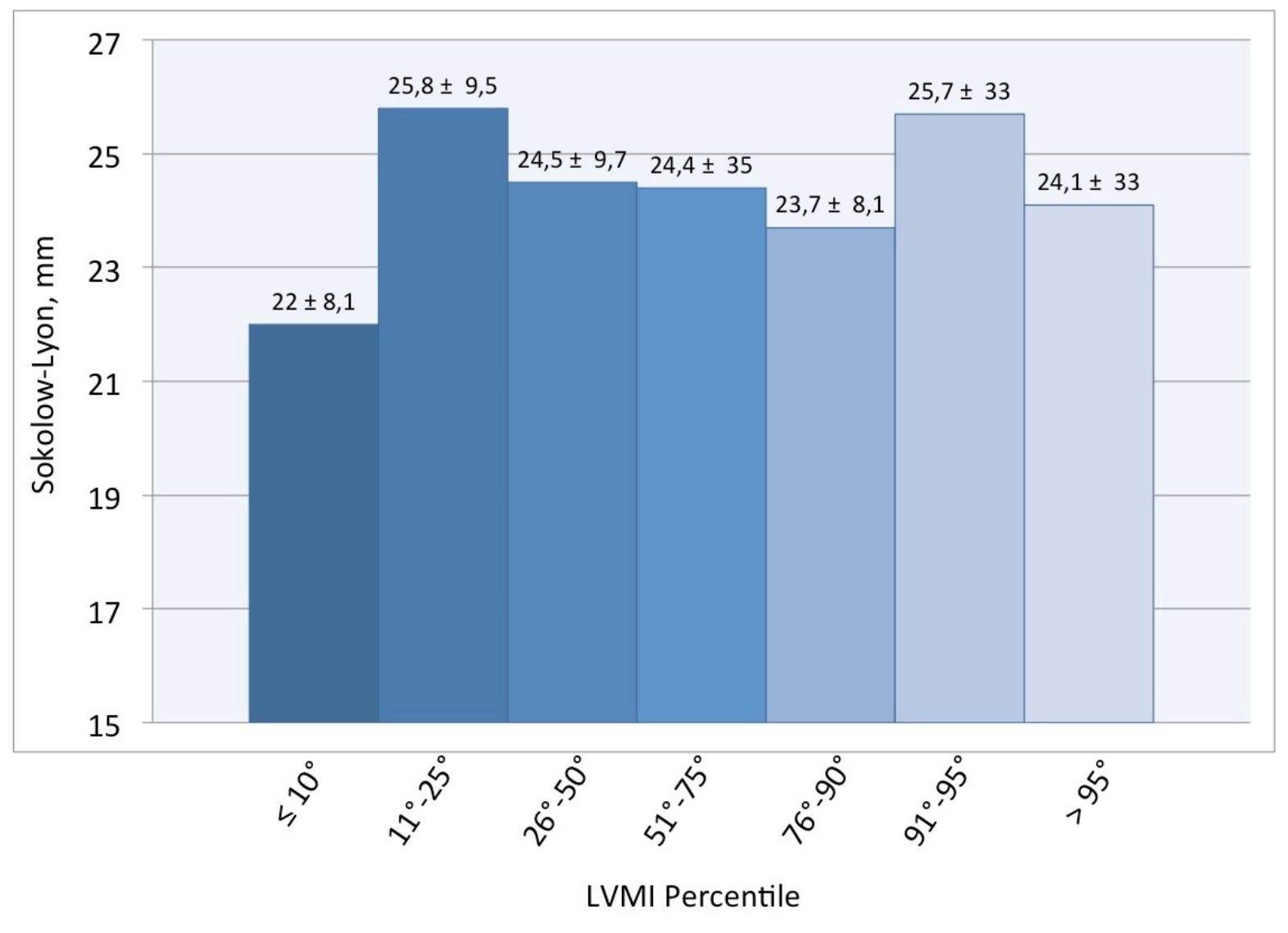

425 Figure 2. Mean values of Sokolow-Lyon according to LVMI percentiles.

426

427

428

429

430

431 
433 Figure 3
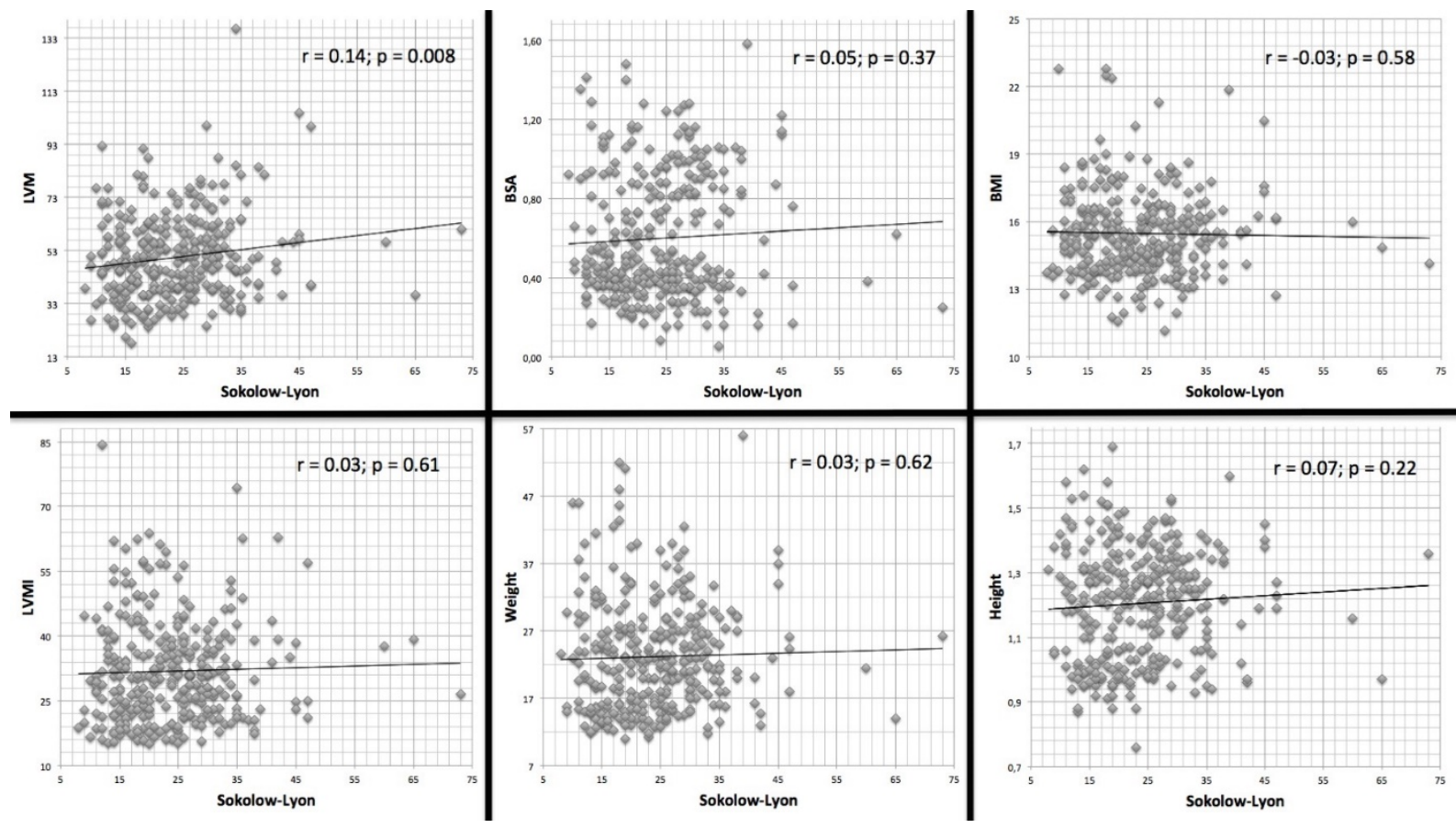

435

Figure 3. Correlation between ECG Sokolow-Lyon formula with echocardiographic LV mass

436 indices and anthropometric parameters. 

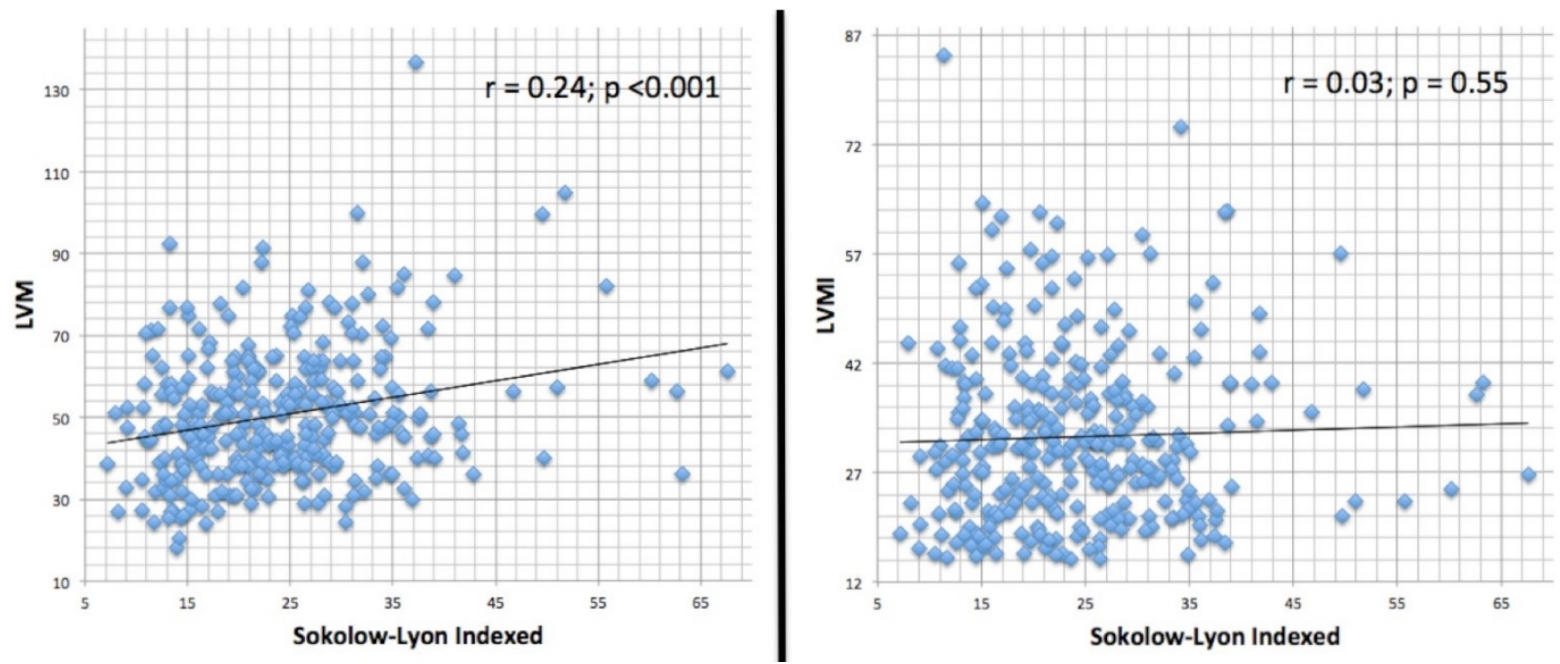

Figure 4. Correlation between ECG Sokolow-Lyon indexed to BMI and echocardiographic LV

mass indices. 


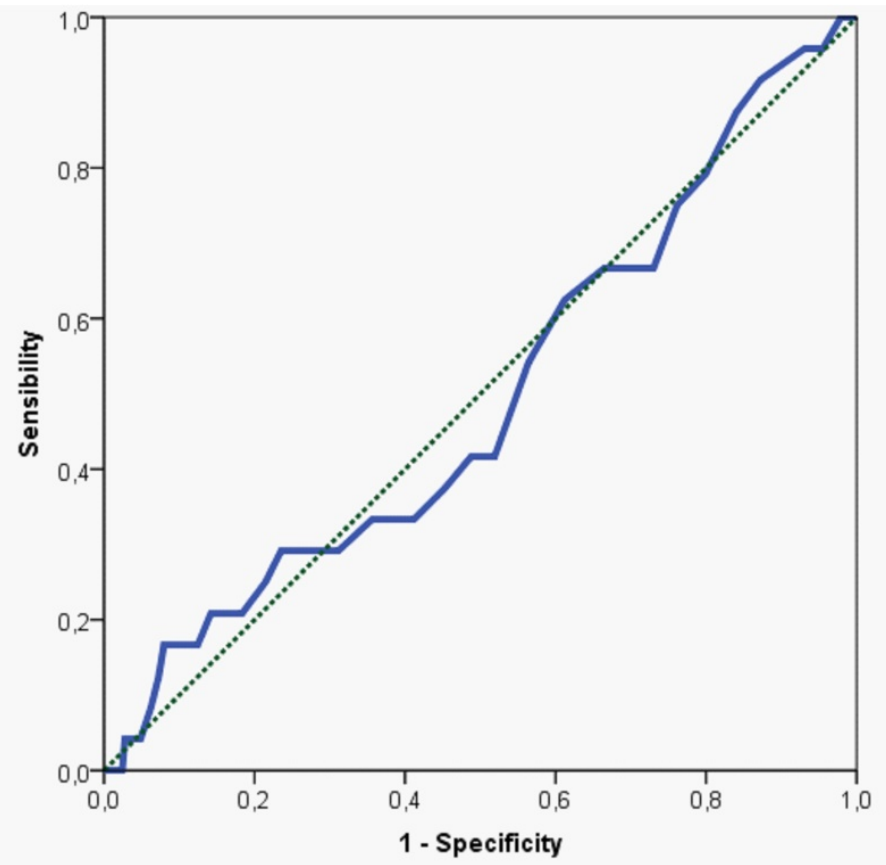

466 Figure 5. ROC curve between LVMI g/m².7 and LVH evaluated through Sokolow-Lyon indexed. 
475

476

477

478

479

480 Tables

481 Table 1. Characteristics of study population.

\begin{tabular}{lc}
\hline $\mathrm{N}^{\circ}$ of children & 313 \\
Male, $\mathrm{n}(\%)$ & $146(47)$ \\
Age, years & $7,8 \pm 3$ \\
Height, cm & $120 \pm 20$ \\
Weight, kg & $23,2 \pm 8,2$ \\
BMI, kg/m ${ }^{2}$ & $15,5 \pm 1,9$ \\
BSA & $0,6 \pm 0,3$ \\
SP, mmHg & $113 \pm 8$ \\
DP, mmHg & $70 \pm 7$ \\
Heart murmur, $\mathrm{n}(\%)$ & $36(12)$ \\
\hline \multicolumn{1}{c}{$E C G$} & $85 \pm 13$ \\
\hline Sinus arrhythmia, $\mathrm{n}(\%)$ & $59(19)$ \\
HR, beats & $103 \pm 18$ \\
PR segment, msec & $140 \pm 25$ \\
QRort PR segment, $\mathrm{n}(\%)$ & $7(2)$ \\
\hline
\end{tabular}


Axis, degrees

Axial deviation, $\mathrm{n}(\%)$

T wave abnormalities, n (\%)

LVH, n (\%)

Sokolow-Lyon, mm

Sokolow-Lyon Indexed, mm

I degree AV block

IV conduction delay, $\mathrm{n}(\%)$

Early repolarization, n (\%)

Ventricular extrasystoles, n (\%)

Supra ventricular extrasystoles, n (\%)

QT interval, msec

QTc, msec
$56 \pm 31$

$67(21)$

$28(9)$

$23,9 \pm 9,2$

$24,1 \pm 9,8$

$1(0,3)$

$1(0,3)$

$364 \pm 41$

$411 \pm 48$

\section{Echocardiography}

LVEDD, mm

IVS, mm

PW, mm

LVM, g
$35 \pm 4$

$6,3 \pm 1,3$

$5,3 \pm 0,9$

$50,5 \pm 16$

482 The numbers are expressed as numerical values (\%) or mean \pm standard deviation.

483 Abbreviations. AV: atrio-ventricular; BMI: body mass index; BSA: body surface area; DP: 484 diastolic pressure; HR: heart rate; IV: intra-ventricular; IVS: inter-ventricular septum; LVEDD: 485 left ventricular end-diastolic diameter; LVH: left ventricular hypertrophy; LVM: left ventricular 486 mass; PW: posterior wall; SP: systolic pressure. 


\begin{tabular}{|c|c|c|c|c|c|c|}
\hline & $\begin{array}{l}\text { Overall } \\
(n=313)\end{array}$ & $\begin{array}{c}\text { ECG-LVH } \\
\quad(n=28)\end{array}$ & Sensitivity. & Specificity & PPV & NPV \\
\hline LVMI $>95^{\circ}$ percentile & 40 & 5 & $13 \%$ & $92 \%$ & $18 \%$ & $88 \%$ \\
\hline $\mathrm{LVMI}^{2.7}\left(>51 \mathrm{~g} / \mathrm{m}^{2.7}\right)$ & $31,9 \pm 11,8(24)$ & $32,6 \pm 45,9(3)$ & $13 \%$ & $91 \%$ & $11 \%$ & $93 \%$ \\
\hline $\operatorname{LVMI}^{\mathrm{w}}(>3.4 \mathrm{~g} / \mathrm{kg})$ & $2,3 \pm 3(19)$ & $2,4 \pm 3,4(3)$ & $16 \%$ & $91 \%$ & $11 \%$ & $94 \%$ \\
\hline
\end{tabular}
predicting value; PPV: positive predicting value.

505

506

507

508 
512

513

514

515

516

517

518

519

520

521

522

Table 3. Distribution of children with LVH diagnosed with ECG among LVMI percentiles.

\begin{tabular}{lccccccc}
\hline & \multicolumn{7}{c}{ LVMI percentiles } \\
& $\leq 10^{\circ}$ & $11^{\circ}-25^{\circ}$ & $26^{\circ}-50^{\circ}$ & $51^{\circ}-75^{\circ}$ & $76^{\circ}-90^{\circ}$ & $91^{\circ}-95^{\circ}$ & $>95^{\circ}$ \\
ECG-LVH, n & $8 / 86$ & $4 / 32$ & $3 / 57$ & $4 / 55$ & $2 / 30$ & $2 / 13$ & $5 / 40$ \\
$(\%)$ & $(9,3)$ & $(12,5)$ & $(5,2)$ & $(7,2)$ & $(6,6)$ & $(15,3)$ & $(12,4)$
\end{tabular}

523 Abbreviations. LVM: left ventricular mass; LVMI: left ventricular mass indexed.

524

525

526 